\title{
Birth controls (contraceptive) methods and human immunodeficiency virus/sexually transmitted infections risk perception among Namibian university students
}

\author{
Toyin O. Jenyo ${ }^{1 *}$, Tony I. Ojiezeh ${ }^{2}$
}

\author{
${ }^{1}$ Department of Public Health and Policy, University of Liverpool, Liverpool, UK \\ ${ }^{2}$ Department of Medical Laboratory Science, Afe Babalola University, Ado Ekiti, Nigeria
}

Received: 05 September 2016

Accepted: 01 October 2016

\section{*Correspondence: \\ Dr. Toyin O. Jenyo, \\ E-mail: toynet74@yahoo.com}

Copyright: (c) the author(s), publisher and licensee Medip Academy. This is an open-access article distributed under the terms of the Creative Commons Attribution Non-Commercial License, which permits unrestricted non-commercial use, distribution, and reproduction in any medium, provided the original work is properly cited.

\begin{abstract}
Background: The question of why are so many of these young girls getting pregnant, is routinely asked, and sometimes contemptuously answered. Accurate information on effectiveness, failures and side effects of different methods of contraception use, have direct relation with the level of their usage among teaming youths.

Methods: Data was collected using self-completed questionnaires for quantitative cross-sectional survey among students in classes selected through simple random sampling in each stratum (University Campus). Relationship between independent variables (method of contraception, misconceptions about the role of contraceptives in preventing HIV/STIs and Risk of infections) and dependent variable (multiple sexual partners) was measured using multivariate model of logistic regression analysis.

Results: The most common contraceptive methods used by students or their partners were condom (71\%), withdrawal $(20.6 \%)$, and birth control pills $(7.2 \%)$, only $2 \%$ used other methods as birth control method, in spite of that, $6.3 \%$ got pregnant or impregnated someone. There was a high incidence of multiple sexual partners among the respondents, only $23.3 \%$ of the respondents believed they were at risk of HIV/STIs infections, while $40.0 \%$ believed they were not at risk, $36.7 \%$ were not definite of their risk status and only $79.9 \%$ of the participants have tested for HIV infection to determine their status.

Conclusions: The most important factor influencing the choice of contraceptive method among young people is its efficacy in prevention of pregnancy. Unprotected sex may not only lead to unplanned pregnancy but HIV/STIs infections and the risk of infection is increased with multiple sexual partners. Thus, the real need for early education on sex and sexuality and also suggest that Government at all level should step-up campaign on contraceptive use and associated risk of non-compliance.
\end{abstract}

Keywords: Birth control, HIV/STIs risk, Multiple partners, Perception

\section{INTRODUCTION}

Contraception is considered to be a major tool to achieve a good sexual and reproductive health, 'one central indicator in reproductive health surrounds the use of contraceptives'. The most important factor influencing the choice of contraceptive method among young people is its efficacy in prevention of pregnancy while the least important is the possibility of altering the menstrual pattern. ${ }^{2}$ The most important factor influencing the choice of contraceptive methods among young people show that STIs might not be a priority in their contraception. Therefore the contraceptive users might be more predisposed to STIs including HIV.

Based on Health Belief model of contraceptive use, contraceptive users are rational (weighing cost against benefit of contraceptive choice) and based the 
contraceptive use behaviour on the available information. $^{3}$ Therefore, accurate information on effectiveness, failures and side effects of different methods of contraception will determine the level of their usage. Although this might not be all that are considered, socio economic factors that determine the affordability/accessibility and acceptability of different contraceptive method can override the 'rational decisionmaking process. In discussing contraceptive methods, particularly their effectiveness, it is important to understand the term contraceptive methods failure and user failure. Method failure occurred when a contraceptive method is ineffective due to a defect on the product itself while user failure is due to incorrect or inconsistent use of the product. ${ }^{4}$

There has been controversy on how effective male latex condom is in preventing conception and transmission of STIs. Studies on the effectiveness of male latex condom in preventing conception and transmission of STIs gave a wide range of condoms effectiveness (prevention of conception and transmission of STIs) and failures (condoms breakage and slipping). With factors like consistency of condoms use, ethnicity, income level and engagement in high-risk sexual behavior, such as having multiple partners and anal intercourse playing major role in the variation. ${ }^{5-8}$ For example studies conducted on sero-discordant heterosexual couples (i.e., in which one partner is HIV positive and the other HIV negative) show that latex condom protects against HIV with infection rate of $0-2 \%$ among the couple who used latex condom consistently compared with infection rate of $10 \%-15 \%$ among couple were not consistent in the use of latex condom. 5,6 Another study showed that among people using condoms for the first time, pregnancy rate was only $2 \%$ among consistent users during the first year of use, while inconsistent users had a $12 \%$ pregnancy rate. ${ }^{8}$ Research conducted on lubricated latex condom failure in the Dominican Republic, Ghana, Kenya, Mali, Mexico, Nepal, Sri Lanka and the United States showed that condom breakage rates during vaginal intercourse range from $0.6 \%$ in Sri Lanka to $13.3 \%$ in Ghana. Condom slipping rate was highest in Kenya where it was 9.3\%, with most of the remaining sites reporting rates below $4 \%$. Combining breakage and slippage rate, total condom failure rates range from $3.8 \%$ to $13.3 \%$. ${ }^{9}$ These outcomes make the condoms failure more of user failure. But the level of failure and the difficulty in differentiating methods failure from user failure made the supporters of abstinence to declare latex condoms as ineffective and unreliable in preventing pregnancy and STIs. They also advocated for a change of the label on the condoms package to something that reflect the accurate level of effectiveness of condom, but the supporters of condom use argued that changing the label might reduce people confidence in condom leading to increase in the spread of HIV infection and other STIs. ${ }^{10}$ Therefore, to achieve maximum protection by using condoms, they must be used consistently and correctly. ${ }^{11}$ However, Latex condom was also found to have little or no effect on the transmission of genital ulcer, human papillomavirus (HPV) and can only reduce the risk of genital herpes, syphilis and chancroid only when the infected area is protected. $^{12,13}$

There has been speculation that hormonal contraceptive (HC) might increase the risk of HIV infection; affect the progression of HIV infection to AIDS in HIV positive patients and alter HIV patient response to Highly Active Anti-Retroviral Therapy (HAART). Some prospective studies showed that there is an increase in the risk of acquiring HIV infection among sero-discordant couples using HC particularly injectables. ${ }^{14,15}$ While the works of Kiddugavu et al, Myer et al and Morrison et al did not show any form of association. ${ }^{16-18}$ It is also important to note that birth control pills cannot protect individuals from sexually transmitted infections (STIs), including HIV/AIDS. They only protect against pregnancy. All birth control methods work the best if used correctly and consistently. Sometimes doctors don't explain how to use a method because they assume you already know. In related studies, increased risk of acquiring/transmitting HIV among women and their partners has been associated with injectable hormonal contraceptives and one of the major confounding factors in these studies is multiple sexual partners. Having multiple sexual partners has been proved to be associated with contraceptive use. $^{17,19-22}$

Namibia is one of the Southern African countries located at the South-Western Africa, with $37 \%$ of the population are under $15 y e a r s$ of age. ${ }^{23}$ Namibia is a middle income country but has one of the most skewed incomes per capital in the world. Two thirds of Namibian population live in the rural areas. On the average in Namibia like most African countries, about half all women use contraceptives $(46.6 \%)$ and injectable hormonal contraceptives is the predominant method, with other methods such as condom use being low. ${ }^{1,24}$ With the existing high incidence of HIV among Namibian young men and women aged 15-24 and increasing burden of HIV infection among youth, it therefore, becomes imperative to examine the factors: birth control methods and perception of young people of contraceptives use, which could be related to the number of sexual partners they may be exposed to. Perhaps, the data obtained from this study might bridge the information gap among Namibian, and elucidate us on the root course of the right shift in HIV/STI infection among young people in the recent years.

\section{METHODS}

Quantitative methodology was used in the conduct of this study, the research was a cross-sectional survey, with an aim to determine contraceptive use among Namibian University students' and establish the association between contraceptive use and the likelihood of having multiple sexual partners. The dependent variable $(\mathrm{dVs})$ was having multiple sexual partners; while independent 
variables (idVs) were contraceptive use and method of contraception.

The population studied consists of undergraduate students in three campuses of the only University in Namibia (University of Namibia (UNAM)) in Oshana Region, Northern part of Namibia.

Four hundred and twenty two subjects (422) respondents were contacted for the study. The sample size was calculated using confidence level $=95 \%$, and the prevalence of contraceptive use among sexually active young women in Namibia which is $52 \%$ from earlier records. Sample size was calculated using Aday and Cornelius and considered $10 \%$ attrition. Stratified and simple random sampling was used by dividing the sample size into strata based on the campuses in Oshana Region. $^{25}$ A contact session with the lecturers and students was arranged to give the details of the study. Then, each student in the randomly selected classes was given a combined participant information sheet and questionnaires. Those who consented to participate in the study answered the questionnaires while others returned theirs. Ethical approval was obtained from the University of Liverpool Research Ethics Committee and the Biomedical Research Ethics Committee (BREC) in the Ministry of Health and Social Services, Namibia.

The inclusion criteria for participation were 19 - 25 years old students of the University of Namibia campuses in Oshana Region. Students above 25year or below 19year of age were excluded from the study. Most students at the University fall within the age group of 19 - 25years. It was expected that good percentage of students in this age group will be sexually active. ${ }^{26}$

The data collection tool (questionnaires) was adapted from the ACHA-NCHA questionnaires on sexual behaviour, perceptions, and contraception with alpha scores for sex-related behaviours $=0.67 .^{27} \mathrm{~A}$ pilot study was carried out on 12 students of University of Namibia, Oshana Region and slight adjustments was made on alternatives/possible answers based on the need during analysis prior to data collection. Data was collected over 3 weeks from October 29 to November 16, 2012.

IBM-SPSS (Statistical Package for Social Science) version 20 was used for the analysis. Descriptive statistics and cross tabulations were calculated to display the socio-demographic distribution of the participants and characterize sexual behaviour.

\section{RESULTS}

Among sexually active students, the most common contraceptive methods used by students or their partners to prevent pregnancy in the most recent vaginal sex were condom, withdrawal, and birth control pills. About seventy one percent $(176 / 249)$ of sexually active students used condom as birth control method, $20.6 \%$ (51/249) of them used withdrawal as birth control method, and 7.2\% (18/249) of them used birth control pills as birth control method. While less than $3 \%$ of them used Depo-Provera (injection) or Norplant (Implant) or Diaphram/Cervical cap/Sponge or Spermicide (e.g. foams) or Fertility awareness (calendar, mucous, basal body temperature) as birth control method in the last vaginal sex. $2.3 \%(4 / 176)$ of respondent did not use anything as birth control method, $64.2 \%$ (113/176) always use condom as means of birth control in the last vaginal intercourse within 30 days past. $17.4 \%$ (57/327) of the students with history of vaginal sex used emergency contraceptive to prevent pregnancy in the last vaginal sex within the last 12 months.

Table 1: The common birth control methods and HIV/STIs perception among university students.

\begin{tabular}{|c|c|c|}
\hline \multirow[b]{2}{*}{ Behaviours } & Number & $\%$ \\
\hline & \multicolumn{2}{|c|}{$\begin{array}{l}\text { Most common birth control } \\
\text { methods for most recent act of } \\
\text { vaginal intercourse }(\mathrm{N}=\mathbf{2 4 9})\end{array}$} \\
\hline Birth control pills & 18 & 7.2 \\
\hline Condom & 176 & 70.7 \\
\hline Withdrawal & 51 & 20.5 \\
\hline \multirow[t]{2}{*}{$\begin{array}{l}\text { Others (hormonal, } \\
\text { implants, foam } \\
\text { etc.) }\end{array}$} & 4 & 1.6 \\
\hline & \multicolumn{2}{|c|}{$\begin{array}{l}\text { Frequency of Condom use during } \\
\text { vaginal Intercourse within last } 30 \\
\text { days }(\mathrm{N}=176)\end{array}$} \\
\hline Never & 4 & 2.3 \\
\hline Rarely & 6 & 3.4 \\
\hline Sometimes & 24 & 13.6 \\
\hline Mostly & 29 & 16.5 \\
\hline \multirow[t]{2}{*}{ Always } & 113 & 64.2 \\
\hline & \multicolumn{2}{|c|}{$\begin{array}{l}\text { Other sexual and reproductive } \\
\text { health behaviours }\end{array}$} \\
\hline $\begin{array}{l}\text { Emergency } \\
\text { contraception use } \\
\text { in last } 12 \text { months } \\
(\mathrm{N}=327)\end{array}$ & 57 & 17.4 \\
\hline $\begin{array}{l}\text { Unintentional } \\
\text { pregnancy within } \\
\text { last } 12 \text { months }(\mathrm{N} \\
=319)\end{array}$ & 20 & 6.3 \\
\hline $\begin{array}{l}\text { History of HIV } \\
\text { testing }(\mathrm{N}=333)\end{array}$ & 266 & 79.9 \\
\hline
\end{tabular}

Eighty nine percent of the students believed condom is an effective contraceptive in prevention of HIV/ STIs (though not reported in this paper), and with high level of incidence of multiple sexual partners among the respondents, only $23.3 \%$ (49/210) of the respondents believed they were at risk of HIV/STI infections, while $40.0 \%(84 / 210)$ believed they were not at risk, and $36.7 \%$ (77/210) were not definite of their risk status. Despite the consequences of their exposure to HIV/STIs, only $79.9 \%$ (266/333) of the participants have tested for HIV infection to determine their status. 


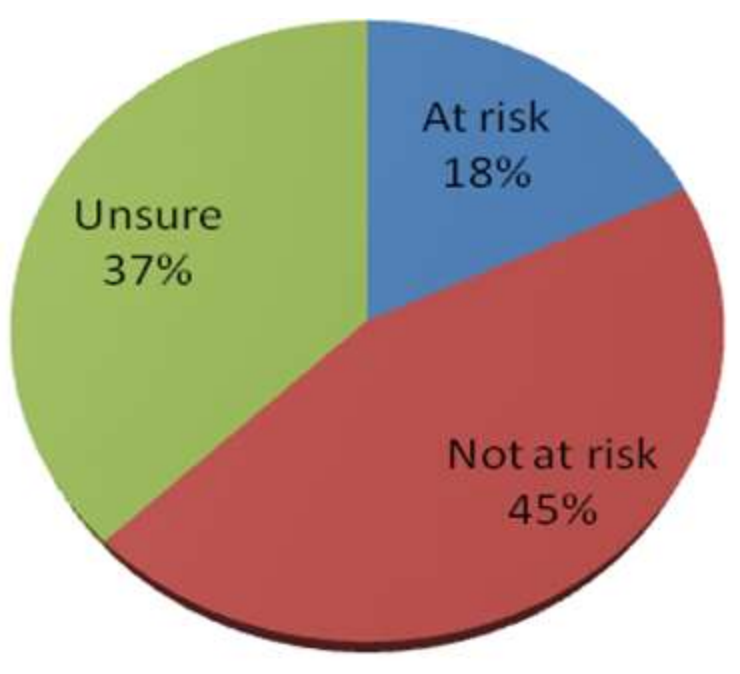

Figure 1: HIV/STIs risk perception and multiple sexual partners among Namibian university students.

\section{DISCUSSION}

Some birth control methods can take time and practice to learn, for example, some people don't know you can put on a male condom "inside out." Also, not everyone knows you need to leave a little space at the tip of the condom for the sperm and fluid when a man ejaculates, or has an orgasm. However, in view of increasing incidence of HIV infection and unplanned pregnancy among young people, it becomes imperative to understand how contraceptive use among students affects risky sexual behaviour, such as multiple sexual partner and poor perception of HIV/STIs risk in relation to birth control. The fact that, there was no data on this aspect of youth in Namibia necessitated the research, to provide data that will provide and improving the quality of family planning programme in the country.

Condoms, pills (Combined Oral Contraceptives) and injectables occupy the first three positions in the contraceptive use prevalence among young women in most of the African countries including Namibia [28-31]. The commonest method of contraception used among these students was condom in our findings; this is in agreement with the studies conducted among female students of higher institution in Nigeria and Lesotho by Abiodun and Balogun and, Akintade et al respectively. ${ }^{30,32}$ Next to that, is withdrawal method and then birth control pills, although majority of the students were catering for HIV/STIs with the use of condoms, significant percentage were still depending on withdrawal method. Withdrawal method was not considered to be very effective in preventing pregnancy and does not protect against HIV/STIs according to World Health Organization. ${ }^{33}$ The preponderance of withdrawal method among the students or their partners predicts an increased risk of HIV/STIs. Although, it is generally belief that condom is an effective contraceptive in preventing HIV/STIs. Despite the level of contraceptive use, significant number of students $(6.3 \%)$ got impregnated or impregnated someone within the last 12 months. The implication of these is that there is a level of compromise in the contraceptive use, which may not be unconnected to methods failure and user failure; this also predicts the level of exposure to HIV/STIs infection among the study group.

We also observed that there was a strong and significant positive association between having multiple sexual partners and contraceptive pills method as a means of birth control during most recent vaginal intercourse and those who perceived that they were at risk of HIV/STI infection. While the association was strong and significantly negative with those who reported that they or their partners have used withdrawal as birth control method for most recent vaginal intercourse. Our findings concur with the reports of Indongo and Winskell et al. ${ }^{33,34}$ This attribute may not be unconnected to the influence of education on those factors that determine the use of contraceptives among youths and also educational level of all the participants in this study is virtually the same. Some of the Socio- demographic factors like age, marital status, educational level, and number of children and residential area (urban/rural), and socio-economic factors like high wealth quintile and employment status and other factors like transactional sex, alcohol use, and numbers of sexual partners may have significant influence on contraceptive use. We therefore, suggest further studies be carried out on the social demographic and economic factors on contraceptive use among young people.

This study was limited to the University students in Northern campuses. Therefore, education, an important factor influencing sexual behaviour and contraceptive use was not included in this study since all the respondents were within the same level of education. The finding of this study is limited to the young people with education level above secondary school. Wider population could be covered with similar study, which will give a generalized result. Also, similar study can be conducted in the Southern campuses of University of Namibia, where white and mixed Namibian are likely to be better represented in such study. Studying the level of Utilization of available Adolescent Friendly Health Services can also give an idea of the accessibility of reproductive services to the young people in the Namibia. Qualitative study will give an in-depth understanding of the relationship between birth control pills and multiple sexual partners. This type of study will be answering questions on causality by explaining 'why' and 'how' the relationship was established. The roles of alcohol use and male gender in this association can be better understood through the qualitative study.

\section{CONCLUSION}

The most important factor influencing the choice of contraceptive method among young people is its efficacy in prevention of pregnancy. Unprotected sex may not only lead to unplanned pregnancy but HIV/STIs 
infections. The risk of infections is increase with multiple partners. However, sexually active should endeavour to seek and receive adequate and detail information about birth control and then assume some responsibility for the prevention of unwanted pregnancies and HIV/STI infections. Hence, the real need for early sex and sexuality education.

\section{ACKNOWLEDGMENTS}

Authors would like to thanks to Dr. Adedayo A. Ogunmokun, Ms Hilkka T. Udjombala and Mr. Moses Hidengwa, the deputy deans of the three campuses of University of Namibia used for the study, for making the procedures easier through their leading roles in their campuses.

Funding: No funding sources

Conflict of interest: None declared

Ethical approval: The study was approved by the Institutional Ethics Committee

\section{REFERENCES}

1. WHO. Women and health: today's evidence tomorrow's agenda. London, WHO. 2009.

2. Bharadwaj P, Akintomide H, Brima N, Copas A, D'Souza R. Determinants of long-acting reversible contraceptive (LARC) use by adolescent girls and young women. The European Journal of Contraception and Reproductive Health Care. 2012;17:298-306.

3. Hall KS. The Health Belief Model Can Guide Modern Contraceptive Behavior Research and Practice' Journal of Midwifery and Women's Health. 2012;57(1):74-81.

4. Haignere CS, Gold R, McDanel HJ. Adolescent Abstinence and Condom Use: Are We Sure We Are Really Teaching What is Safe?' Health Educ Behav. 1999;26:43.

5. CDC. Update: Barrier protection against HIV infection and other sexually transmitted diseases. MMWR. 1993;42:589-91, 97.

6. de Vincenzi IA. Longitudinal study of human immunodeficiency virus transmission by heterosexual partners' New England Journal of Medicine. 1994;331:341-6.

7. Grady WR, Tanfer K. Condom Breakage and Slippage among Men in the United States' Family Planning Perspectives. 1994;26(3):107-12.

8. Trussell J, Hatcher RA, Cates W, Stewart FH, Kost K. Contraceptive failure in the US; An update. Stud Fam Plann. 1990;21:51.

9. Steiner M, Piedrahita C, Joanis C, Glover L, Spruyt A. Condom Breakage and Slippage Rates Among Study Participants in Eight Countries. International Family Planning Perspectives. 1994;20(2):55-8.

10. Trenton NJ. How well do condoms work against STDs? Debate over whether warning labels should be changed'. 2009. Available from http://www.msnbc.msn.com/id/8399212/ns/healthsexual_health/t/how-well-do-condoms-work-againststds/\#.UEuF56Ahzow. Accessed on 06/09/2012.

11. CDC. 2011. Male Latex Condoms and Sexually Transmitted Diseases: Fact Sheet for Public Health Personnel. Available from http://www.cdc.gov/condomeffectiveness/brief.htm. Accessed on 08/09/2012.

12. CDC. 2002. Male Latex Condoms and Sexually Transmitted Diseases: Fact Sheet for Public Health Personnel. Available from http://www.cdc.gov/condomeffectiveness/latex.htm. Accessed on 06/09/2012.

13. Holmes KK, Levine R, Weaver M. Effectiveness of condoms in preventing sexually transmitted infections. Bulletin of the World Health Organization. 2004;82:454-61.

14. Heffron R, Donnell D, Rees H, Celum C, Were E, Mugo N, et al. Hormonal contraceptive use and risk of HIV-1 transmission: a prospective cohort analysis' International AIDS Society IAS. Available from http://pag.ias2011.org/abstracts.aspx?aid=1715. Accessed on 12/03/2012.

15. Wand H, Ramjee G. The effects of injectable hormonal contraceptives on HIV seroconversion and on sexually transmitted infections. AIDS. 2012;26(3):375-80.

16. Kiddugavu M, Makumbi F, Wawer MJ, Serwadda D, Sewankambo NK, Wabwire-Mangen F, et al. Hormonal contraceptive use and HIV-1 infection in a population-based cohort in Rakai, Uganda' AIDS (London, England). 2013;17(2):233-40.

17. Myer L, Denny L, Wright TC, Kuhn L. Prospective study of hormonal contraception and women's risk of HIV infection in South Africa' International Journal of Epidemiology. 2007;36(1):166-6.

18. Morrison CS, Skoler-Karpoff S, Kwok C, Chen PL, Wijgert J, Gehret-Plagianos M, et al. Hormonal contraception and the risk of HIV acquisition among women in South Africa'. AIDS. 2012;26(4):497-504.

19. Ahmed S, Lutalo T, Wawer M, Serwadda D, Sewankambo NK. HIV incidence and sexually transmitted disease prevalence associated with condom use: a population study in Rakai, Uganda. AIDS. 2012;15(16):2171-9.

20. Kapiga SH, Lugalla JL. Sexual behaviour patterns and condom use in Tanzania:results from the 1996 Demographic and Health Survey. Aids Care. 2012;14(4):455-69.

21. Yeatman S, Urassa M, Isingo R, Zaba B. Sexual Behaviour of Ever Users of Contraception and Its Implications in a High Prevalence HIV Population in Northwest Tanzania. Population Association of America 2005 Annual Meeting Program. 2005:10.

22. Wawer MJ, Gray RH. Challenges in assessing associations between hormonal contraceptive use and the risks of HIV-1 acquisition and transmission. Future Microbiol. 2012;7(3):315-8.

23. MOHSS. United Nation General Assembly Special Session (UNGASS): Country report. Available from 
https://www.unaids.org/fr/dataanalysis/monitoringco untryprogress/2010progressreportssubmittedbycount ries/file. Accessed on 26/07/2012.

24. MOHSS and Macro International Inc. 2008. Namibia Demographic and Health survey 2006-07; pp. 50. Available from: http://www.healthnet.org.na/documents/reports/Nami bia\%20Demographic\%20and\%20Health\%20Survey \%202006-07.pdf. Accessed on 06/07/2011.

25. Aday LA, Cornelius LJ. Designing and Conducting Health Surveys: a Comprehensive Guide 3rd Ed USA: John Wiley. 2006. pp. 160

26. Lawoyin OO, Kanthula RM. Factors that Influence Attitudes and Sexual Behaviour among Constituency
Youth Workers in Oshana Region, Namibia, African Journal of Reproductive Health. 2010;14(1):55-69.

27. Sang LT, Sally B, Helen HM. Sexual and Reproductive Health Behaviors of California Community College Students' Journal of American College Health. 2011;59(8):744-50.

28. Oye-Adeniran BA, Adewole IF, Odeyemi KA, Ekanem EE, Umoh AV. Contraceptive prevalence among young women in Nigeria. Journal of Obstetrics and Gynaecology. 2011;25(2):182-5.

29. MacPhail C, Pettifor AE, Pascoe S, Rees HV. Contraception use and pregnancy among 15-24 year old South African women: a nationally representative cross-sectional survey. BMC Medicine. 2007;7:31.

Cite this article as: Jenyo TO, Ojiezeh TI. Birth controls (contraceptive) methods and human immunodeficiency virus/sexually transmitted infections risk perception among Namibian university students. Int J Reprod Contracept Obstet Gynecol 2016;5:3722-7. 